\title{
Eğitim Kaynaklarının Kullanım Etkinliği Üzerine Bir Uluslararası Karşılaştırma
}

\author{
Başak Erdem-Kara ${ }^{1}$, Osman Tat ${ }^{1}$ \\ ${ }^{1}$ Eğitim Bilimleri Enstitüsü, Hacettepe Üniversitesi, Ankara, Türkiye
}

Sorumlu Yazar: Osman Tat, osmntt@gmail.com

Makale Türü: Araştırma Makalesi

Bilgilendirme: Bu makale 27. Uluslararası Eğitim Bilimleri Kongresi’nde sözlü bildiri olarak sunulmuştur.

Kaynak Gösterimi: Erdem-Kara, B., \& Tat, O. (2019). Eğitim kaynaklarının kullanım etkinliği üzerine bir uluslararası karşılaştırma. Eğitimde Kuram ve Uygulama, 15(2), 153-170. doi: 10.17244/eku.478617

\section{An International Comparison on Efficiency in Use of Educational Resources}

\author{
Başak Erdem Kara ${ }^{1}$, Osman Tat ${ }^{1}$ \\ ${ }^{I}$ Graduate School of Educational Sciences, Hacettepe University, Ankara, Turkey
}

Corresponding Author: Osman Tat, osmntt@gmail.com

Article Type: Reresearch Article

Bilgilendirme: This study was presented at the 27th International Congress of Educational Sciences.

To Cite This Article: Erdem-Kara, B., \& Tat, O. (2019). Eğitim kaynaklarının kullanım etkinliği üzerine bir uluslararası karşılaştırma. Eğitimde Kuram ve Uygulama, 15(2), 153-170. doi: 10.17244/eku.478617 


\title{
Eğitim Kaynaklarının Kullanım Etkinliği Üzerine Bir Uluslararası Karşılaştırma
}

\author{
Başak Erdem-Kara ${ }^{1}$, Osman Tat ${ }^{1}$ \\ ${ }^{1}$ Eğitim Bilimleri Enstitüsü, Hacettepe Üniversitesi, Ankara, Türkiye \\ ORCID: https://orcid.org/0000-0003-3066-2892 \\ ORCID: https://orcid.org/0000-0003-2950-9647
}

\section{Öz}

İlk olarak 2003 yılında uygulanan ve sonraki her üç yılda bir tekrarlanan Uluslararası Öğrenci Değerlendirme Programı (PISA) sonuçları öğrencilerin bilgi ve beceri düzeylerinin ülkeler arasında karşılaştırılmasında, eğitim politikalarının belirlenmesinde ve eğitim sistemlerinin güçlü ve zayıf yönlerinin ortaya konmasında kullanılan oldukça kapsamlı göstergelerdir. Uluslararası Öğrenci Değerlendirme Programı'nda öğrencilerin farkı alanlara ilişkin performansları ölçülürken aynı zamanda katılımcı ülkelerin eğitimini etkileyen alt yapı ve insan kaynakları gibi birçok girdiye ait veri de toplanmaktadır. $\mathrm{Bu}$ çalışmada, Uluslararası Öğrenci Değerlendirme Programı'nın son üç dönemine göre Türkiye'nin, eğitim kaynaklarını etkin kullanımı bakımından Ekonomik Kalkınma ve İş birliği Örgütü (OECD) üyeleri içerisindeki konumu, etkinlik oranının yıllar içerisindeki değişimi veri zarflama analizi yardımı ile incelenmiştir. Ayrıca Türkiye'nin hangi girdilerde nasıl bir değişikliğe gitmesi gerektiği incelenmiştir. Araştırmada Uluslararası Öğrenci Değerlendirme Programı'nın 2009, 2012 ve 2015 dönemlerine katılan OECD ülkelerinin öğrenci test sonuçları ve okul anketi verileri kullanılmıştır. Araştırma sonucunda, Türkiye'nin her üç dönemde de kaynaklarını etkin kullanamadığı ve etkin kullanma oranının genel OECD ortalamasının belirgin bir biçimde altında olduğu belirlenmiştir. Ayrıca Türkiye'nin etkinlik oranının 2015 uygulamasında oldukça düştüğü tespit edilmiştir. Her üç dönem için de Türkiye'nin öğrenci/öğretmen oranını düşürmesi gerektiği sonucuna ulaşılmıştır.
Makale Bilgisi

Anahtar Kelimeler: Kaynak, OECD, PISA, Veri zarflama, Verimlilik

Makale Geçmişi:

Geliş: 05 Kasım 2018

Düzeltme: 20 Şubat 2019

Kabul: 20 Şubat 2019

Makale Türü: Araştırma Makalesi 


\section{An International Comparison on Efficiency in Use of Educational Resources}

\begin{abstract}
The Programme for International Student Assessment (PISA) was conducted first in 2003 and has been repeated in each following three-year period. The result of the programme is one of the most extensive indicators that is used in international comparison of students in terms of skills and knowledge, determination of direction of educational policy and in detection of weak and adequate aspects of educational systems. The program does not only aim to evaluate the performance of students in various fields but also gather data about factors affecting educational systems like human resources or background variables across countries. In this research, the authors aim to investigate the position of Turkey in relation to the OECD countries in terms of effective use of resources in the last three cycles of The Programme for International Student Assessment and the change of the efficiency rate in those cycles. The data of this study consist of student performance results in mathematics tests and four school questionnaire variables in the last three study cycles. It is detected that Turkey could not benefit from its resources efficiently in any cycle and the average efficiency rate is significantly below the OECD average. Another prominent finding of this research according to all three cycles is that Turkey should decrease the student/teacher ratio to be an efficient country member.
\end{abstract}

Article Info

Keywords: Data envelopment analysis, Efficiency, OECD, PISA, Resource

\section{Article History:}

Received: 05 November 2018

Revised: 20 February 2019

Accepted: 20 February 2019

Article Type: Research Article 


\section{Giriș}

Uluslararası Öğrenci Değerlendirme Programı (PISA-Programme for International Student Assesment), birçok ülkenin katılımıyla gerçekleşen ve 15 yaş grubu öğrencilerin modern toplumda yerlerini alabilmeleri için gerekli temel bilgi ve becerilere ne derece sahip olduklarını ölçmeyi amaçlayan bir uygulamadır (OECD, 2017). OECD tarafindan düzenlenen PISA uygulamasına ilişkin sonuçlar; öğrencilerin bilgi ve becerilerinin ülkeler arası karşılaştırmasını yapmak, eğitim düzeyinin yükseltilmesi amaciyla standartlar oluşturmak ve eğitim sistemlerinin güçlü ve zayıf yanlarını belirlemek için kullanılabilmektedir (Taş, Arıcı, Ozarkan, \& Özgürlük, 2016). PISA sonuçları, yönetici ve eğitimcilere, yüksek performans gösteren ülkelerin eğitim sistemlerinin özelliklerini inceleyerek, kendi ülkelerine adapte edebilecekleri etkili politikalar belirleyebilmeleri noktasında yardımcı olur (Yuan, Ying \& Shan, 2016). Benzer şekilde; Aydın, Selvitopu ve Kaya (2018), ülkelerin eğitim sistemleri ve genel ekonomik görünümleriyle alakalı çok boyutlu ve boylamsal veriler sağlaması nedeni ile PISA sonuçlarının önemli olduğunu belirtmiştir.

İlk olarak 2000 y1lında düzenlenen ve sonraki her üç yılda bir tekrarlanan PISA uygulamasına, Türkiye 2003 yılında dâhil olmuştur (OECD, 2017). Matematik okuryazarlığı sonuçlarına bakıldığında, son üç uygulamada Türkiye ortalaması hem OECD ortalamasının hem de katılan tüm ülkelerin ortalamasının altında kalmıştır. Son üç uygulamada Matematik Okuryazarlı̆ğ değerlendirmesinden elde edilen sonuçlar Tablo 1'de sunulmuştur.

Tablo 1. Y1llara Göre PISA Matematik Okuryazarlığı Ortalama Puanları

\begin{tabular}{llll}
\hline & PISA 2009 & PISA 2012 & PISA 2015 \\
\cline { 2 - 4 } OECD Ortalamas1 & 496 & 494 & 490 \\
Tüm Ülkeler Ortalaması & 465 & 470 & 461 \\
Türkiye Ortalaması & 445 & 448 & 420 \\
Türkiye Siralamas1 & 41 & 44 & 50 \\
Katılımcı Ülke Sayıs1 & 65 & 65 & 72 \\
\hline
\end{tabular}

Kaynak: Taş, Arıcı, Ozarkan, \& Özgürlük (2016)

Tablo 1'deki verilere göre; tüm ülkeler ortalamasının 465, OECD ortalamasının 496 olduğu PISA 2009 uygulamasında, Türkiye 445 ortalamayla 65 ülke arasında 41. sırada yer almıştır. PISA 2012 uygulamasında, tüm ülkeler ortalamas 470 ve OECD ortalaması 494 iken, Türkiye ortalaması 448'dir ve 65 ülke arasında 44. sirada yer almıştır. PISA 2015 matematik okuryazarlığı sonuçlarına bakıldığında ise, genel ortalama 461, OECD ortalaması 490 iken, Türkiye ortalaması 420 olmuştur ve 72 ülke arasından 50. sırada yer alınmıştır. Son üç uygulamada da üyesi olduğu OECD'nin ortalamasının bariz bir biçimde altında bulunan Türkiye için bu durumun nedenlerinin detaylı bir biçimde incelenmesi oldukça önemlidir.

Türkiye'nin PISA uygulamalarındaki düşük performansının arkasında eğitim, sosyal yaşam ve ekonomi ile alakalı birçok etkenin bulunduğu düşünülmektedir (Yorulmaz, Çolak, \& Ekinci, 2017). Savaşçı ve Tomul (2013), öğrencilerin akademik başarıları üzerinde etkili olabilecek önemli faktörlerden birinin eğitimde kullanılan kaynaklar olduğunu belirtmiştir. OECD (2016) raporunda ise, eğitime yapılan yatırımların ve kullanılan kaynakların öğrenci başarısı üzerinde etkisi olduğu ancak bu etkinin düşük düzeyde kaldığı; önemli olan noktanın kaynakların niteliği ve ne şekilde kullanıldığı olduğu belirtilmiştir. Bu nedenle, yöneticilerin, okulların ve ailelerin odaklanması gereken nokta eğitimsel kaynakların etkili kullanılıp kullanılmadığı ve hangi kaynakların öğrenci performanslarını artırabileceğidir. Benzer şekilde, Berberoğlu ve Kalender (2005) eğitimde yapılan yatırımların etkililiğinin önemine vurgu yapmıştır. Bu bilgiler 1şı̆̆ında, Türkiye'nin kaynaklarını ne derece etkin kullandığının ve bu durumun diğer ülkelerle karşılaştırılmasının, Türkiye'nin düşük performansına ilişkin bilgi sunabileceği düşünülmüştür. Yapılan karşılaştırmalar, eğitime yapılan yatırımların ve kullanılan kaynakların öğrenci performansı üzerindeki etkisi konusunda fikir vermiştir.

Literatür incelendiğinde, PISA verileri kullanılarak yapılan veri zarflama analizi (VZA) çalışmalarına rastlanmış, ancak bu çalışmaların genellikle ülkelerin kendi içerisindeki okulların etkinlik karşılaştırmaları ile sınırlı kaldığ1 görülmüştür (Agasisti, 2013; Demir \& Depren, 2009; Demir, Depren, \& Kılıç, 2010; Yalçın \& Tavşancıl, 2014). Agasisti (2013), PISA 2006 verisini kullanarak İtalya'daki okulların etkinlik değerlerini veri zarflama analizi 
ile hesaplamış ve okul karşılaştırması yapmıştır. Türkiye'deki çalışmalara bakıldığında, Demir ve Depren (2009), PISA 2006 verileri üzerinden okullar bazında bir etkinlik ölçümü yapmış ve Türkiye'deki 147 okulu incelemişlerdir. Demir, Depren ve Kılıç (2010) tarafından yapılan bir diğer çalışmada, Türkiye'nin farklı bölgelerindeki ortaöğretim okullarının etkinliği PISA 2003 verisi üzerinden analiz edilmiştir. Yalçın ve Tavşancıl (2014) tarafından yapılan çalışmada ise, PISA 2003, 2006 ve 2009 yıllarında ortak olarak bulunan Türkiye'deki okul türlerinin etkinliklerini VZA yöntemiyle karşılaştırmıştır. Veri zarflama yöntemi kullanılarak ülkeler arası etkinlik karşılaştırmalarının yapıldığı yalnızca iki çalışmaya rastlanmıştır (Gavurova, Kocisova, Belas, \& Krajcşj, 2017; Lorcu \& Acar-Bolat, 2015). Gavurova ve diğerleri (2017), Avrupa Birliği ülkelerinin ortaöğretim eğitim sistemlerini göreli etkinlik değerlerini PISA 2015 verisi üzerinden hesaplamışlardır. Benzer şekilde, Lorcu ve Acar-Bolat (2015), Türkiye'deki ve Avrupa Birliği üyesi ülkelerdeki ortaöğretim düzeyindeki eğitimin etkinlik değerlerini, PISA 2009 verilerini kullanarak VZA yöntemiyle karşılaştırmıştır. Çalışmalar incelendiğinde, kaynakların etkin kullanımı yönünden Türkiye'nin diğer ülkelerle karşılaştırıldığı çalışmaların sınırlı olduğu; ayrıca sonuçların tek bir PISA uygulama dönemi ile sınırlı kaldığı görülmüştür. Sonuçların boylamsal açıdan değerlendirildiği bir çalışmaya rastlanamamıştır. Türkiye'nin etkin kaynak kullanımı bağlamında yıllar içerisindeki durumunun ve diğer ülkeler arasındaki yerinin detaylı incelenmesinin faydalı bilgiler sağlayacağı düşünülmektedir.

Bu bağlamda, çalışma kapsamında Türkiye'nin kaynaklarını ne derece etkin kullandığını ve performansını etkileyen olası faktörleri incelemek amacıyla veri zarflama analizi yapılmıştır. Bu amaç doğrultusunda, hangi OECD ülkelerinin kaynaklarını etkin kullanabildikleri ve Türkiye'nin OECD ülkeleri arasındaki yeri 2009, 2012, 2015 yıllarına göre ayrı ayrı incelenmiş ve değişim yorumlanmıştır. Böylelikle, Türkiye'nin hem etkin kaynak kullanımı noktasında yıllar içerisindeki durumu, hem de OECD ülkeleri arasındaki yerinin incelenmesi amaçlanmıştır. Bu amaç doğrultusunda aşağıdaki problemlere yanıt aranmıştı;;

1. PISA 2009, 2012 ve 2015 uygulaması sonuçlarına göre;

a) Kaynaklarını etkin kullanan ülkeler hangileridir?

b) Kaynakların etkin kullanımı bakımından Türkiye'nin diğer ülkeler arasındaki yeri nasıldır?

c) Türkiye'nin etkinlik değerini yükseltmek için yapılabilecek değişiklikler nelerdir?

\section{Yöntem}

OECD ülkelerinin etkin kaynak kullanımını ve Türkiye'nin bu ülkeler arasındaki yerini üç döneme ait PISA verileri üzerinden ortaya koyma amacı taşıyan bu araştırma tarama modelindedir. Tarama araştırmaları, geçmişte ya da şu anda var olan bir durumu, mevcut şekliyle betimlemeyi amaçlayan araştırma modelleridir (Karasar, 2012).

\section{Evren Örneklem}

Çalışma kapsamında, PISA 2009, 2012 ve 2015 uygulamasından OECD üyesi ülkelere ilişkin verilere ulaşılmıştır. PISA'ya katılan OECD ülkesi sayısı 2009 ve 2012 yılları için 34, 2015 y1lı için ise 35'tir. Ancak analizler kapsamında, girdi değişkenlerine ilişkin kayıp veri bulunduran ülkeler analiz dışı bırakılmıştır. Analize, 2009 ve 2012 yılları için 33, 2015 yılı içinse 32 ülkeyle devam edilmiştir.

\section{Veri Toplama Araçları}

Veri toplama aracı olarak PISA 2009, 2012 ve 2015 uygulamalarında kullanılan okul anketleri ve başarı testi kullanılmış, veriler OECD'nin internet sayfasından sağlanmıştır. Okul anketleri incelenerek, her üç uygulamada da tüm OECD ülkeleri için ortak olan değişkenler belirlenmiş ve girdi değişkenleri olarak kullanılmıştır. Üç yıldan elde edilen matematik başarısı puanları ise çıktı değişkeni olarak alınmıştır.

\section{Veri Analizi}

Analiz için EMS paket programı kullanılmış, girdi odaklı CCR modeline dayalı olarak analiz yapılmıştır. Analiz sonrası elde edilen sonuçlara göre etkin olan ülkeler ile etkin olmayan ülkeler karşılaştırılarak değerlendirme yapılmıştır.

\section{Veri Zarflama Analizi}

İlk olarak Farrell tarafından 1957'de ortaya atılan, Charnes, Cooper ve Rhodes (1978) ve Banker, Charnes ve Cooper (1984)'ün katkılarıyla geliştirilen veri zarflama analizi, etkinlik ölçümünde kullanılan ve matematiksel programlamaya dayalı olan non-parametrik bir tekniktir (Thanassoulis, Portela, \& Despic, 2008). Girdi veya çıktı bakımından birbirine benzeyen karar verme birimlerinin göreli etkinliklerini ölçmek üzere geliştirilmiştir. Girdiler ve 
çıktıların farklı ölçek düzeylerinde olması veya farklı birimlerle ölçülmesi sorun teşkil etmemektedir. Bu yöntem sayesinde, her bir karar verme biriminde kaynakların ve etkinlik değerlerinin ölçümü yapılabilir ve her bir karar verme biriminin bir diğerine göre göreli etkinlik değeri hesaplanabilir (Charnes, Cooper, \& Rhodes, 1978). Yuan, Ying ve Shan (2016) ise veri zarflama analizini, belirli bir zaman aralığında çoklu girdiler kullanarak çoklu çıktılar üreten karar verme birimlerinin (KVB) göreli etkinliklerini ölçmek için uygulanan non-parametrik bir teknik olarak tanımlamıştır. Bu yönteme dayalı olarak birden fazla girdi ve çıktının bulunduğu ve karşılaştırmanın zorlaştığ1 durumlarda, karar verme birimlerinin göreli performansları değerlendirilir.

Karar verme birimi, kaynakların kullanımı bakımından etkinliği incelenen, birbirine benzeyen girdiler yardımıyla benzer çıktılar üreten işletme, ekonomik kuruluş ve okul benzeri birimler olarak tanımlanabilir. Analiz kapsamında, tüm KVB'ler için etkinlik puanı hesaplanır. Ayrıca, etkin olmayan KVB'ler için girdi ve çıktılarda yapılabilecek gerekli iyileştirmelere ilişkin bilgi sağlanır (Bektaş, 2007).

KVB'ler tarafından kullanılan kaynaklar girdi; ortaya çıkan kazanç, sonuç ve hizmet ise çıktı olarak tanımlanabilir. Etkinlik ise mevcut girdilerle ne derece etkin üretim yapılabildiğinin ölçüsüdür; mevcut çıktı ile maksimum çıktı arasındaki oranı ortaya koyar. Etkinlik oranının bire yaklaşıyor olması, girdilerin etkin kullanım derecesinin arttığının göstergesidir (Suiçmez, 2002).

Literatürde en yaygın kullanılan iki model CCR (Charnes, Cooper, Rhodes) ve BCC (Banker, Charnes, Cooper) modelleridir (Demir \& Bakırc1, 2014). CCR modelinde, ölçeğe göre sabit getiri varsayımından hareket edilir. Ölçeğe göre sabit getiri, bir birimin girdisindeki artışın çıktısında eşit bir artış meydana getirmesi anlamına gelir. Yani, birimin ölçeğinin verimlilik üzerinde etkisi yoktur (Bektaş, 2007). BCC modelinde ise, ölçeğe göre değişken getiri varsayımı vardır ve benzer ölçekteki birimler birbirleri arasında karşılaştırılabilmektedir (Çakmak \& Örkcü, 2016). Hem BCC hem de CCR modeli için girdiye ve çıktıya yönelik modeller bulunmaktadır. Girdi minimizasyonunun amaçlandığı girdiye yönelik modelde, belirli bir çıktı bileşimini en etkin şekilde üretebilmek için sağlanabilecek en uygun girdi bileşimi elde edilmeye çalışılır. Çıktı seviyesi sabit tutulurken, etkin olmayan KVB'lere ilişkin girdi bileşiminin ne derece azaltılması gerektiği araştırılır. Yani, çıktıya en az girdi ile ulaşılmaya çalışı1ır (Erpolat, 2011; Sarı, 2015). Çıktı maksimizasyonunun hedeflendiği çıktıya yönelik modelde ise, belirli bir girdi bileşimi ile elde edilebilecek maksimum çıtı bileşimi araştırılır. Girdi seviyesi sabit tutularak etkin olmayan KVB'lerin etkin hale gelebilmesi için çıktıların ne kadar artırılması gerektiğini ortaya koyar (Demir \& Bakırc1, 2014; Erpolat, 2011; Sarı, 2015).

VZA'nın en temel avantajı, çok sayıda girdi veya çıktı bulunduğu durumlarda veya girdi ve çıktıların çok farklı birimlere sahip olduğu durumlarda bile karar verme birimleri arasında karşılaştırma yapabilmeyi mümkün kılmasıdır (Tanassoulis, Portela \& Allen, 2004; Özkan-Aksu \& Temel-Gencer, 2018). Etkinlik analizi ve performans değerlendirme amacıyla kullanılan bu analizin en yaygın olarak kullanıldığı sektörler; bankacılık, sağlık ve eğitimdir (Aladă̆, Alkan, Güler, \& Özdin, 2018).

Çalışma kapsamında, VZA uygulama aşamaları izlenmiş (Bozdağ, Altan, \& Atan (2000)'den aktaran Bal, 2013; Sarı, 2015) ve izlenen adımlar aşağıda açıklanmıştır.

Adım 1. Karar verme birimlerinin seçilmesi. Yapılan çalışmada OECD ülkeleri karar verme birimleri olarak belirlenmiştir. Her bir ülke için her bir değişkene ilişkin ortalama değeri hesaplanmış ve analize bu değerlerle devam edilmiştir.

Tablo 2. Girdi ve Çıktı Değişkenleri

\begin{tabular}{cl}
\hline \multirow{3}{*}{ Girdi Değişkenleri } & Öğrenci-Öğretmen Oranı \\
& Okul Mevcudu \\
& Tam Zamanlı Öğretmen Sayısı \\
& İternet Erişimi Olan Bilgisayar Oranı \\
\hline Çıktı Değișkenleri & Matematik Okuryazarlığı Puanları \\
\hline
\end{tabular}

Adım 2. Girdi ve çıktı değişkenlerinin belirlenmesi. Çalışma kapsamında 2009, 2012 ve 2015 yıllarına ait PISA veri setlerinden yararlanılmış; bu uygulamalardaki okul anketleri üç y1l için de incelenmiş, OECD ülkeleri için ortak olan beş değişken girdi değişkeni, bu yıllardaki matematik okuryazarlığı puanları ise çıktı değişkeni olarak alınmıştır. Analizde yer alan girdi ve çıktı değişkenleri Tablo 2'de sunulmuştur. 
- Öğrenci-Öğretmen Oranı: Toplam öğrenci sayısının toplam öğretmen sayısına (Yarı zamanlı öğretmenler 0.5, tam zamanlı öğretmenler bir katsayısı ile hesaplanacak şekilde) oranının göstergesi olan bu değişken okullardaki insan kaynağının bir ölçüsüdür (OECD, 2016). Öğretmen-öğrenci oranı eğitime yapılan kaynak yatırımlarının insan kaynakları sınıfında yer almaktadır. OECD (2012) raporunda eğitime harcanan kaynakların önemli göstergelerinden birisi olarak belirtilen bu değişkendeki artış, öğretmen başına düşen öğrenci sayısının artışı anlamına gelmektedir. Döş ve Atalmış (2016), PISA 2006, 2009 ve 2012 verilerini kullanarak yaptıkları araştırmalarında, bu değişkenin okuma, fen ve matematik başarıları ile negatif ilişki içerisinde olduğunu belirtmiştir. Ayrıca, Koç ve Çelik (2015), öğrenci öğretmen oranı ile başarı arasında negatif ilişki olduğunu ifade etmiştir.

- Okul Mevcudu: Okullardaki toplam öğrenci sayısının göstergesidir. Okul müdürleri tarafindan bildirilen bu değer, materyal kaynakları altında yer almaktadır (OECD, 2016). Egalite ve Kisida (2016), okul mevcudu arttıkça öğrencilerin okuma ve matematikteki akademik başarılarının azaldığı sonucuna ulaşmıştır.

- Tam Zamanlı Öğretmen Sayısı: Tüm okul yılının en az \%90'ında öğretmenlik yapanlar tam zamanlı öğretmen olarak düşünülmüştür (OECD, 2014). Kyule, Kangu, Wambua, Mutinda ve Kamau (2014), yarı zamanlı öğretmenlerin geçici sözleşmeleri bulunduğunu ve tecrübelerini ve niteliklerini tam anlamıla gösteremedikleri pozisyonlarda çalıştıklarını ve becerilerini tam olarak kullanamadıklarını belirtmiştir. Ayrıca Leszinske, Joley ve Bryant (2012), yarı-zamanlı öğretmenlerle yapılan anlaşmaların son ana bırakılması sebebiyle, dönem başlamadan önce müfredata ve öğrenciye uyum sağlama, öğretim gerekliliklerini yerine getirme gibi konularda sıkıntı yaşadıklarını belirtmiştir. Bu nedenle, yarı zamanlı öğretmen sayısının akademik başarı ile ters orantılı, tam zamanlı öğretmen sayısının ise doğru orantılı olduğu düşünülmüştür. $\mathrm{Bu}$ değişken analize sokulurken başarı ile ters orantılı olacak şekilde dönüştürülmüştür.

- İnternet Erişimi Olan Bilgisayar Oranı: Okullarda internete bağlı bilgisayar sayısının toplam bilgisayar sayısına oranlanmasıyla hesaplanır. İnternetin birçok eğitimsel konuda bilgi edinebilmek ve grup projelerindeki koordinasyonu sağlamak için değerli bir kaynak olduğunu belirtilmektedir. Bilgisayar, internet, yazılım ve diğer teknolojiler etkileşimli yönleri sayesinde okul çağındaki çocuklara geleneksel yöntemlerin sağlayamadığı olanaklar sağlayabilirler (Cuban, 2001). Ayrıca, evlerinde bilgisayar veya internet erişimi olmayan çocuklar için, okullarda bilgisayar ve internet erişimi olması önemli bir kazançtır. $\mathrm{Bu}$ değişkende meydana gelecek artış, internete bağlı bilgisayar oranının artacağı anlamına gelmektedir. Yani, bu artışın başarıya olumlu yansıyacağı düşünülmektedir. Bundan dolayı VZA analizinin doğası gereği analize sokulurken başarı ile ters orantılı olacak şekilde dönüştürülmüştür.

- Matematik Okuryazarlığı Puanı: Bu değişken öğrenciler tarafindan matematik okuryazarlığı testinden alınan puandır. Çalışma kapsamında kullanılan puan PV1 puanıdır.

Adım 3. Modelin belirlenmesi ve etkinlik ölçümü. Araştırma kapsamında, CCR modeli kullanılmıştır. Eldeki çıktıya en etkin şekilde ulaşabilmek için en uygun olan girdi bileşimine ulaşılmaya çalışılan bu araştırmada, girdiye yönelik model tercih edilmiştir. Temel analiz modellerinde, KVB'lerin göreli etkinliği değerlendirilebilir ancak etkin KVB'lerin siralaması yapılamaz (hepsi '1' etkinlik değerine sahip olur). Bu nedenle etkin KVB'lerin kendi aralarında sıralanabilmeleri için süper etkinlik analizi de uygulanmıştır.

Adım 4. Sonuçların değerlendirilmesi. Verilerin düzenlenmesinden sonra analizler EMS programında yapılmıştır. Etkinlik değeri \%100'ün üzerinde olan ülkeler etkin, diğerleri etkin olmayanlar olarak belirlenmiştir. Sonrasında, etkin olmayan ülkeler için referans almaları gereken ülke seti incelenmiş ve etkin olmayan ülkelerin etkin duruma gelebilmek için girdi değişkenlerinde yapmaları önerilen değişiklikler açıklanmıştır. Elde edilen sonuçlar bulgular bölümünde detaylı bir şekilde anlatılmıştır.

\section{Bulgular}

Üç uygulama yılı için etkinlik değerlere ve girdi değişkenlerinde yapılabilecek değişikliklere ilişkin elde edilen bulgular ayrı ayrı incelenmiştir. Son olarak Türkiye’nin durumu üç uygulama yılı için değerlendirilmiştir.

\section{PISA 2009’a İlişkin Bulgular}


PISA 2009 uygulamasından elde edilen verilere göre, sınava 34 OECD ülkesi katılmış, ancak Fransa kayıp veriler nedeniyle analiz dışı bırakılmıştır. Geriye kalan 33 ülke için etkinlik değerleri hesaplanmış, etkin olmayan ülkelerin girdi değişkenlerinde yapabilecekleri değişiklikler Tablo 3'te sunulmuştur.

Tablo 3. OECD Ülkeleri için Veri Zarflama Analizi Sonuçları (PISA 2009)

\begin{tabular}{|c|c|c|c|c|c|}
\hline & $\begin{array}{c}\text { Etkinlik Değeri } \\
(\%)\end{array}$ & $\begin{array}{c}\text { Öğrenci/ } \\
\text { Öğretmen }\end{array}$ & Okul Mevcudu & $\begin{array}{c}\text { Tam Zamanlı } \\
\text { Öğrt. }\end{array}$ & $\begin{array}{c}\text { İnternete Bağlı } \\
\text { Bilgisayar }\end{array}$ \\
\hline Avustralya & 99.10 & 0 & 0 & 0 & 0 \\
\hline Avusturya & 89.75 & 0.05 & 0 & 0 & 0 \\
\hline Belçika & 103.35 & & & & \\
\hline Kanada & 96.55 & 1.27 & 0 & 0 & 0 \\
\hline İsviçre & 97.71 & 1.56 & 14.26 & 0.02 & 0 \\
\hline Şili & 73.10 & 8.67 & 347.25 & 0 & 0 \\
\hline Çek Cumhuriyeti & 91.44 & 2.27 & 0 & 0 & 0 \\
\hline Almanya & 92.91 & 4.28 & 211.18 & 0 & 0 \\
\hline Danimarka & 93.92 & 0.73 & 17.28 & 0 & 0 \\
\hline İspanya & 95.11 & 1.58 & 0 & 0 & 0 \\
\hline Estonya & 95.60 & 1.14 & 85.3 & 0 & 0 \\
\hline Finlandiya & 110.37 & & & & \\
\hline İngiltere & 93.64 & 0 & 0 & 0 & 0 \\
\hline Yunanistan & 102.23 & & & & \\
\hline Macaristan & 92.35 & 1.58 & 0 & 0 & 0 \\
\hline İrlanda & 89.11 & 2.25 & 84.45 & 0 & 0 \\
\hline İzlanda & 109.54 & & & & \\
\hline İsrail & 76.59 & 1.26 & 0 & 0 & 0 \\
\hline İtalya & 99.97 & 0.43 & 0 & 0 & 0.06 \\
\hline Japonya & 98.58 & 1.44 & 0 & 0 & 0 \\
\hline Kore & 105.07 & & & & \\
\hline Lüksemburg & 105.98 & & & & \\
\hline Meksika & 52.42 & 8.16 & 36.86 & 0.01 & 0 \\
\hline Hollanda & 97.23 & 4.83 & 492.63 & 0 & 0 \\
\hline Norveç & 95.62 & 0.85 & 0 & 0 & 0 \\
\hline Yeni Zelanda & 97.09 & 0 & 0.2 & 0 & 0 \\
\hline Polonya & 94.53 & 0.96 & 0 & 0 & 0 \\
\hline Portekiz & 112.83 & & & & \\
\hline Slovakya & 90.10 & 2.7 & 0 & 0.01 & 0 \\
\hline Slovenya & 106.99 & & & & \\
\hline İsveç & 90.79 & 1.19 & 0 & 0 & 0 \\
\hline Türkiye & 78.19 & 3.05 & 0 & 0 & 0 \\
\hline Amerika & 96.90 & 3.74 & 271.86 & 0 & 0 \\
\hline
\end{tabular}

Tablo 3'teki verilere göre, 33 OECD ülkesinin 8'inin kaynaklarını etkin kullandığg, 25 ülkenin ise bu konuda başarısız olduğu söylenebilir. Burada, etkinlik puanı 100\%'e eşit ve üzerinde olan ülkeler etkin, diğerleri ise etkin olmayan ülkelerdir. Kaynak kullanımı konusunda en etkin ülke Portekiz, en başarısız ülke ise Meksika olmuştur. Ülkelerin etkinlik değerlerine göre sıralaması Şekil 1'de sunulmuştur. 


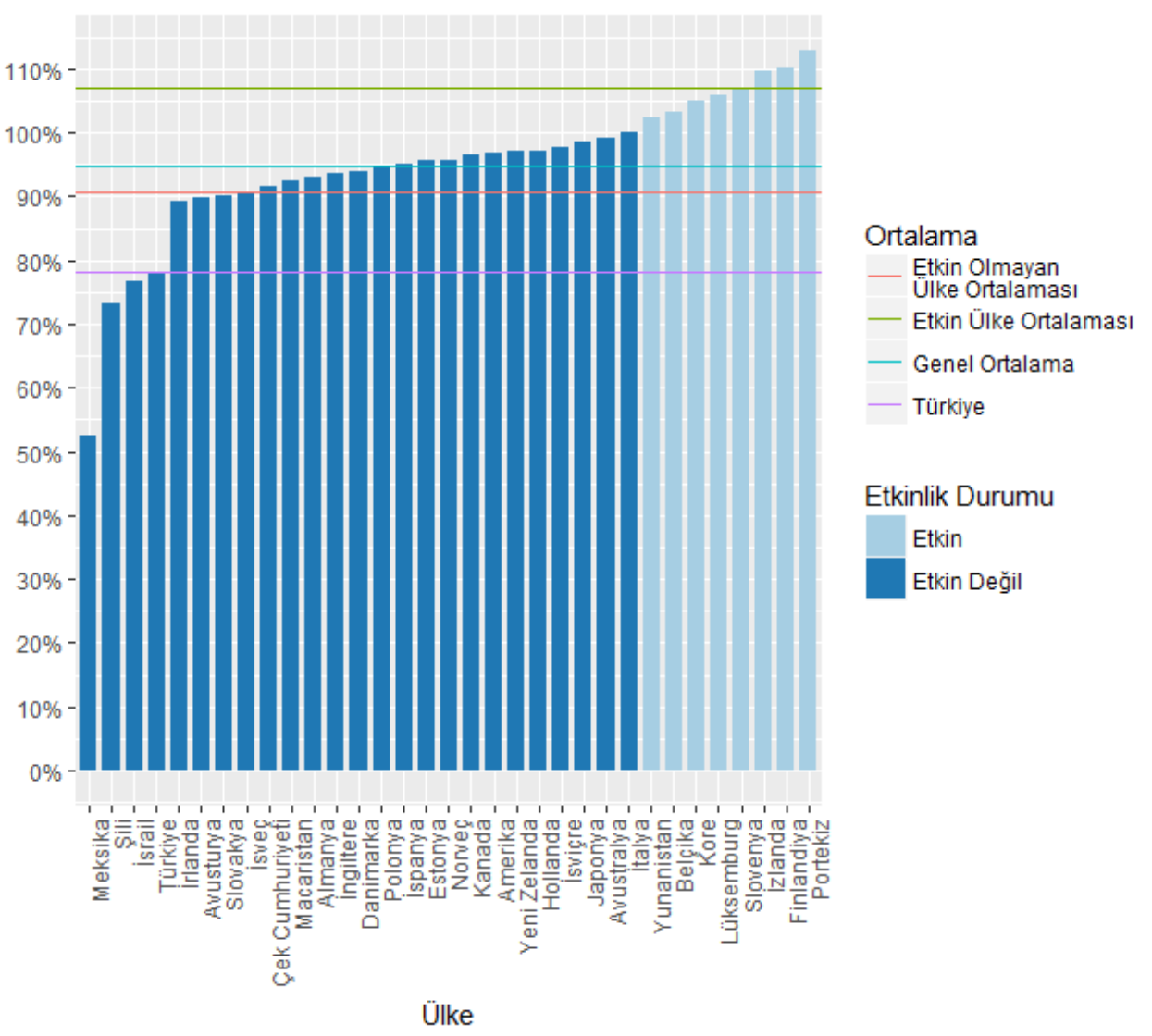

Grafik 1. OECD Ülkelerinin Etkinlik Değerlerine Göre Sıralaması (PISA 2009)

PISA 2009 verilerine göre Türkiye, \%78,19 etkinlik puanı ile etkin olmayan ülkeler arasında yer almaktadır. Şekil 1 incelendiğinde, Türkiye'nin etkin kaynak kullanımı anlamında 33 ülke içerisinde 30. sırada olduğu görülmektedir. Türkiye yaklaşık olarak \%78 etkinlik oranı ile genel etkin olan ülkeler ortalamasının (\%107) oldukça uzağında kalırken genel ortalamanın (\%95) altında kalmaktadır. Etkin olmayan ülkeler ortalamasının (\%91) da yaklaşık 13 puan gerisinde olan Türkiye'nin etkin ülke durumuna gelebilmesi için, Tablo 3'teki değerlere göre, öğrenci/öğretmen oranını 3.05 birim azaltması önerilmektedir. Türkiye için referans setini oluşturan ülkeler ise Finlandiya ve Kore'dir. Türkiye'nin etkin duruma gelebilmek için $\% 32$ oranında Finlandiya'yı, $\% 50$ oranında Kore'yi örnek alması gerekmektedir.

\section{PISA 2012'ye İlişkin Bulgular}

PISA 2012 verilerine göre, uygulamaya katılan OECD ülkesi sayıs1 34'tür. Kayıp veri bulundurması sebebiyle Avusturya veri seti analiz dışı bırakılmış, analize 33 OECD ülkesiyle devam edilmiştir. VZA sonucunda elde edilen etkinlik değerleri ve etkin olmayan ülkelerin girdi değişkenlerinde yapabilecekleri değişikliklere ilişkin bilgiler Tablo 4 'te sunulmuştur.

Tablo 4'teki verilere göre, 33 OECD ülkesinin 11'inin kaynaklarını etkin kullandığı, 22 ülkenin ise etkin kaynak kullanımında başarısız olduğu görülmüştür. Kaynak kullanımının etkinliği konusunda en başarılı ülke Lüksemburg, en başarısız ülke ise 2009 yılındaki gibi yine Meksika olmuştur. Ülkelerin etkinlik değerlerine göre sıralaması Şekil 2'de sunulmuştur.

Şekil 2'ye bakıldığında kaynaklarını en etkin şekilde kullanabilen ülkenin Lüksemburg, bu konuda en başarısız ülkenin ise Meksika olduğu görülmektedir. Türkiye, etkin kaynak kullanımı noktasında en başarısız üç ülkeden biri olmuştur. 2009 yılındaki uygulama sonuçlarına oldukça benzer sonuçların elde edildiği gözlenmektedir. Buna göre Türkiye yaklaşık \%81 etkinlik oranı ile etkin olmayan ülke ortalamasının (\%90) dokuz puan altında kalırken, genel ortalamanın (\%95) 14 puan ve etkin ülke ortalamasının (\%104) yaklaşık 23 puan gerisindedir. 2012 yılı uygulamasında etkin olmayan ülkeler ortalamasının ve genel ortalamanın bir önceki uygulamaya göre değişmediği gözlenirken, Türkiye'nin etkinlik oranın yaklaşık üç puan yükselttiği tespit edilmiştir. Tablo 4'teki sonuçlara göre, Türkiye'nin etkin ülke konumuna gelebilmesi için öğretmen/öğrenci oranını 3.14 birim azaltması gerekmektedir. 
Ayrıca kaynakların etkin kullanımı bakımından Türkiye'nin örnek alması gereken ülkeler ise Kanada, Estonya ve Kore'dir.

Tablo 4. OECD Ülkeleri için Veri Zarflama Analizi Sonuçları (PISA 2012)

\begin{tabular}{|c|c|c|c|c|c|}
\hline & $\begin{array}{c}\text { Etkinlik } \\
\text { Değeri (\%) }\end{array}$ & $\begin{array}{c}\text { Öğrenci// } \\
\text { Öğretmen }\end{array}$ & Okul Mevcudu & $\begin{array}{c}\text { Tam Zamanlı } \\
\text { Öğrt. }\end{array}$ & $\begin{array}{c}\text { İnternete Bağlı } \\
\text { Bilgisayar }\end{array}$ \\
\hline Avustralya & 95.97 & 0 & 43.43 & 0 & 0 \\
\hline Belçika & 105.91 & & & & \\
\hline Kanada & 96.98 & 1.4 & 0 & 0 & 0 \\
\hline İsviçre & 100.96 & & & & \\
\hline Şili & 74.86 & 3.66 & 0 & 0 & 0 \\
\hline Çek Cumhuriyeti & 94.75 & 2.03 & 0 & 0 & 0 \\
\hline Almanya & 95.38 & 1.74 & 0 & 0 & 0 \\
\hline Danimarka & 96.29 & 1.45 & 0 & 0 & 0 \\
\hline İspanya & 92.80 & 0.66 & 0 & 0 & 0 \\
\hline Estonya & 100.09 & & & & \\
\hline Finlandiya & 102.09 & & & & \\
\hline Fransa & 94.09 & 0.57 & 0 & 0 & 0 \\
\hline İngiltere & 91.65 & 0 & 6.01 & 0 & 0 \\
\hline Yunanistan & 94.08 & 0.28 & 0 & 0 & 0.05 \\
\hline Macaristan & 90.91 & 1.19 & 0 & 0 & 0 \\
\hline İrlanda & 95.35 & 1.85 & 0 & 0 & 0 \\
\hline İzlanda & 105.60 & & & & \\
\hline İsrail & 82.62 & 0 & 4.83 & 0 & 0 \\
\hline İtalya & 97.90 & 0.84 & 0 & 0 & 0.05 \\
\hline Japonya & 101.64 & & & & \\
\hline Kore & 105.00 & & & & \\
\hline Lüksemburg & 111.69 & & & & \\
\hline Meksika & 52.88 & 6.36 & 0 & 0 & 0 \\
\hline Hollanda & 97.36 & 0.84 & 0 & 0.01 & 0 \\
\hline Norveç & 94.80 & 0.93 & 0 & 0 & 0 \\
\hline Yeni Zelanda & 93.01 & 0 & 34.02 & 0 & 0 \\
\hline Polonya & 102.74 & & & & \\
\hline Portekiz & 107.65 & & & & \\
\hline Slovakya & 92.29 & 2.55 & 0 & 0 & 0 \\
\hline Slovenya & 105.57 & & & & \\
\hline İsveç & 91.93 & 1.63 & 0 & 0 & 0 \\
\hline Türkiye & 80.98 & 3.14 & 0 & 0 & 0 \\
\hline Amerika & 88.75 & 3.94 & 157.14 & 0 & 0 \\
\hline
\end{tabular}




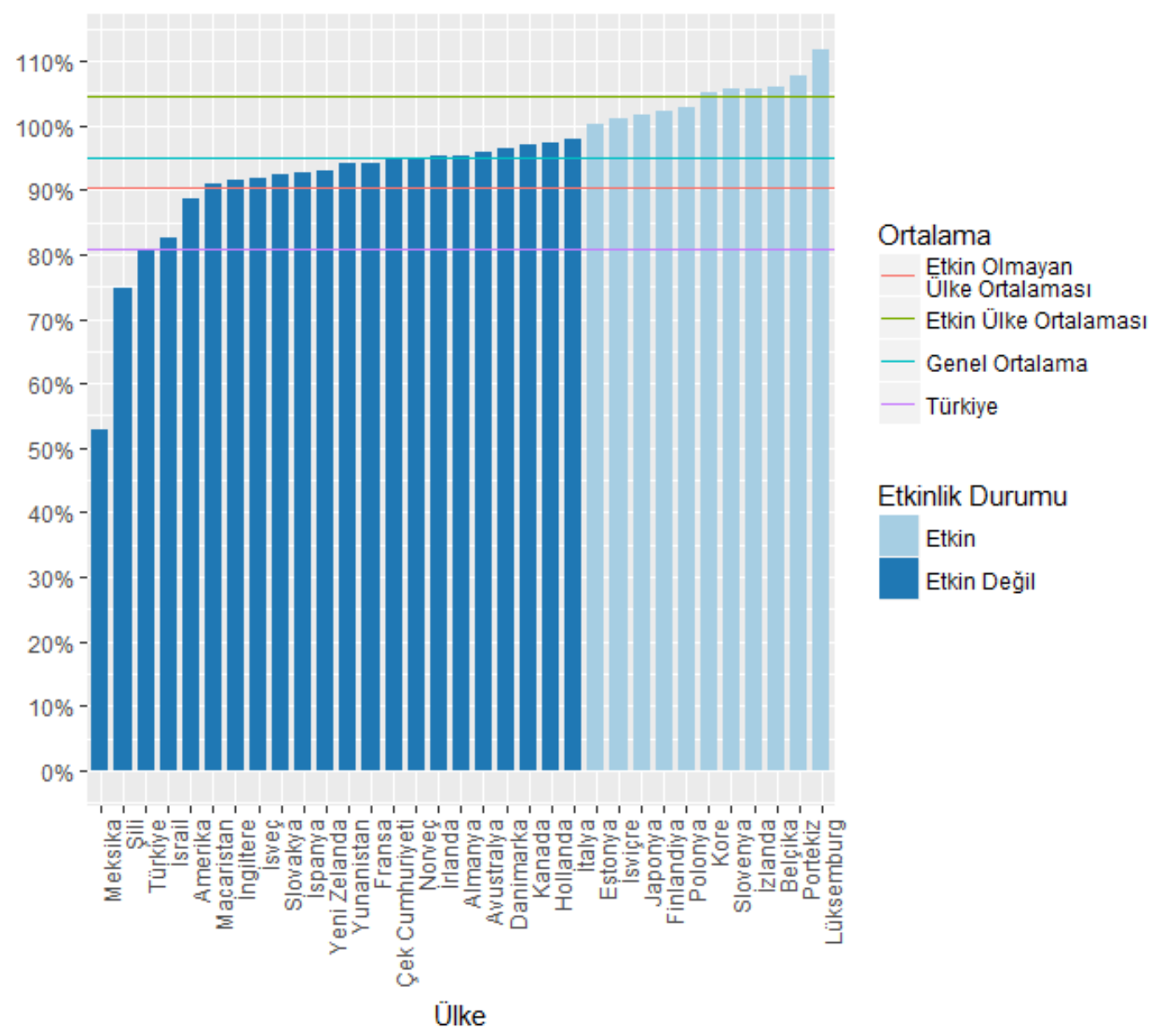

Şekil 2. OECD Ülkelerinin Etkinlik Değerlerine Göre Sıralaması (PISA 2012)

\section{PISA 2015' İliş kin Bulgular}

PISA 2015 verilerine göre, uygulamaya katılan OECD ülkesi sayıs1 35 iken, kayıp veri bulundurması sebebiyle Avusturya, Yeni Zelanda ve İsveç veri seti dışında bırakılmış, analize 32 ülke ile devam edilmiştir. VZA sonucunda elde edilen etkinlik değerleri ve etkin olmayan ülkelerin girdi değişkenlerinde yapabilecekleri değişikliklere ilişkin bilgiler Tablo 5'te sunulmuştur.

Tablo 5 incelendiğinde, 32 ülkenin 11'inin etkin, 21 ülkenin ise etkin olmayan ülke sinıfında olduğu görülmektedir. En etkin ülke \%123,86 oranı ile Portekiz iken, etkinlik değeri en düşük ülke Meksika (\%60.91) olmuştur. Ülkelerin etkinlik değerlerine göre sıralaması Şekil 3'te incelenebilir.

Şekil 3 incelendiğinde, kaynaklarını en etkin kullanan ülkelerin başında Portekiz, Polonya ve Belçika gelirken, bu konudaki en başarısız üç ülke Şili, Türkiye ve Meksika olmuştur. Türkiye yaklaşık olarak \%75 etkinlik oranı ile etkin olmayan ülkeler ortalamasının (\%92) yaklaşık 17 puan, genel ortalamanın (\%97) yaklaşık 22 puan ve etkin olan ülkeler ortalamasının (\%106) 29 puan gerisinde kalmıştır. Ayrıca bu dönemdeki uygulamada etkin olmayan ülkeler ortalamasının ve genel ortalamanın bir önceki uygulamaya göre birkaç birim yükselmesine rağmen Türkiye'nin etkin kullanım oranının aynı kaldığı gözlenmiştir. Türkiye'nin etkin ülke konumuna gelebilmesi için öğretmen/öğrenci oranı girdisini 1.5 birim azaltması önerilmektedir. Türkiye'nin etkin ülke durumuna gelebilmek için örnek alması gereken ülkeler ise Danimarka, Japonya ve Kore'dir. Türkiye ve diğer ülkelerin etkinlik oranlarının yıllara göre nasıl değiştiği Şekil 4'te görülmektedir. 
Tablo 5. OECD Ülkeleri için Veri Zarflama Analizi Sonuçları (PISA 2015)

\begin{tabular}{|c|c|c|c|c|c|}
\hline & $\begin{array}{l}\text { Etkinlik Değeri } \\
(\%)\end{array}$ & $\begin{array}{l}\text { Öğgrenci/ } \\
\text { Ögrretmen }\end{array}$ & Okul Mevcudu & $\begin{array}{l}\text { Tam Zamanlı } \\
\text { Öğrt. }\end{array}$ & $\begin{array}{l}\text { İnternete Bağlı } \\
\text { Bilgisayar }\end{array}$ \\
\hline Avustralya & 97.29 & 0.57 & 0 & 0 & 0 \\
\hline Belçika & 108.33 & & & & \\
\hline Kanada & 99.42 & 1.77 & 0 & 0 & 0 \\
\hline İsviçre & 100.19 & & & & \\
\hline Şili & 76.54 & 2.68 & 0.29 & 0 & 0 \\
\hline Çek Cumhuriyeti & 95.28 & 2.54 & 0 & 0 & 0 \\
\hline Almanya & 95.43 & 1.01 & 0 & 0 & 0 \\
\hline Danimarka & 100.69 & & & & \\
\hline İspanya & 93.82 & 0 & 0 & 0 & 0 \\
\hline Estonya & 100.96 & & & & \\
\hline Finlandiya & 98.26 & 1.04 & 0 & 0 & 0.21 \\
\hline Fransa & 96.00 & 1.29 & 0 & 0 & 0 \\
\hline İngiltere & 94.30 & 0 & 11.25 & 0 & 0 \\
\hline Yunanistan & 100.98 & & & & \\
\hline Macaristan & 97.99 & 1.27 & 0 & 0 & 0.05 \\
\hline İrlanda & 96.40 & 1.33 & 0 & 0 & 0 \\
\hline İzlanda & 93.73 & 0.16 & 0 & 0 & 0 \\
\hline İsrail & 82.11 & 0.89 & 0 & 0 & 0.01 \\
\hline İtalya & 97.86 & 0.91 & 0 & 0 & 0.01 \\
\hline Japonya & 100.15 & & & & \\
\hline Kore & 102.35 & & & & \\
\hline Lüksemburg & 106.59 & & & & \\
\hline Litvanya & 94.34 & 0 & 0 & 0 & 0 \\
\hline Meksika & 60.91 & 7.17 & 37.44 & 0 & 0 \\
\hline Hollanda & 98.46 & 6.55 & 296.37 & 0 & 0 \\
\hline Norveç & 99.39 & 1.29 & 0 & 0.01 & 0 \\
\hline Polonya & 109.53 & & & & \\
\hline Portekiz & 123.86 & & & & \\
\hline Slovakya & 91.81 & 2.77 & 0 & 0.01 & 0 \\
\hline Slovenya & 108.13 & & & & \\
\hline Türkiye & 74.81 & 1.5 & 0 & 0 & 0 \\
\hline Amerika & 92.38 & 2.99 & 148.51 & 0 & 0 \\
\hline
\end{tabular}




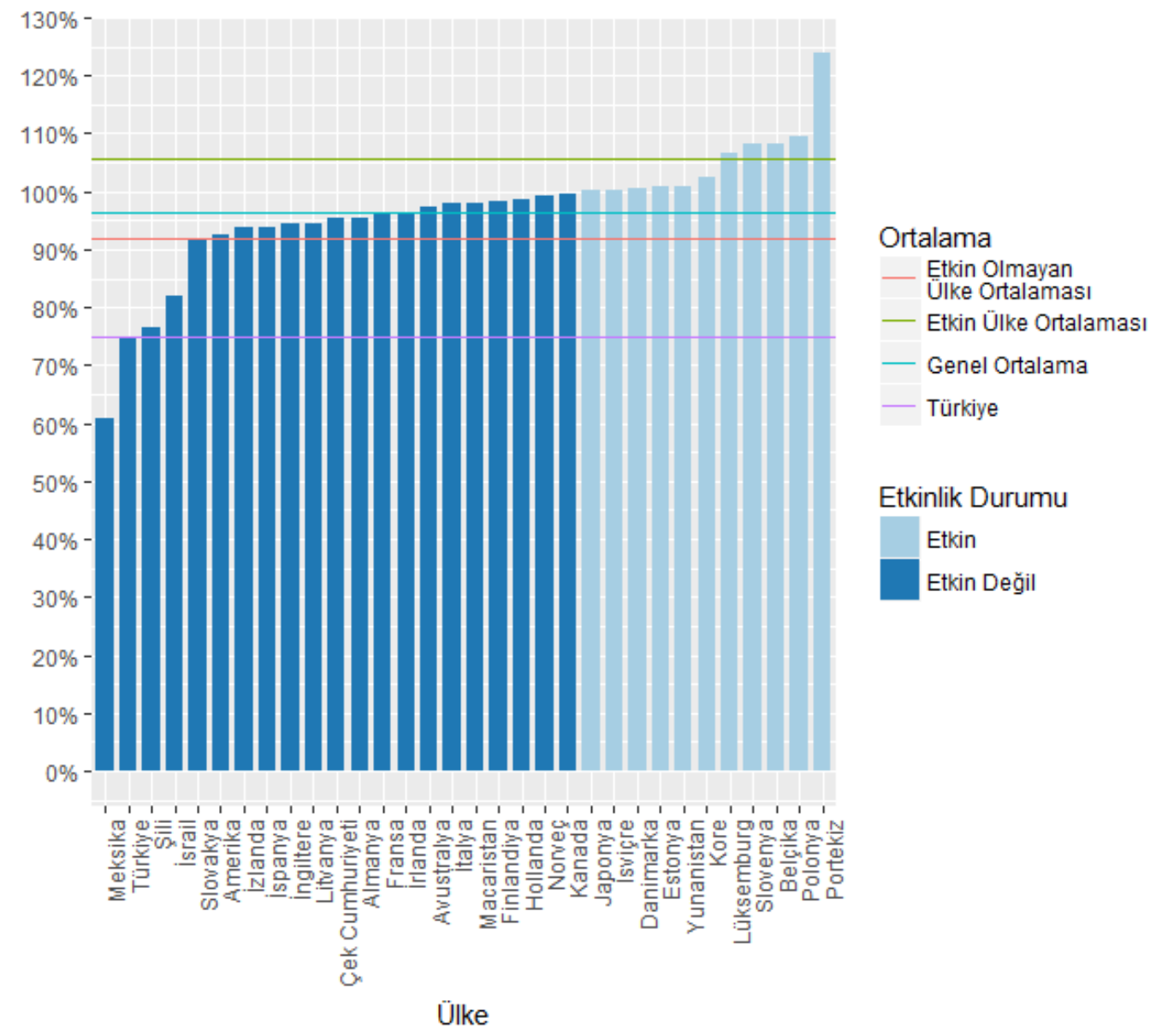

Şekil 3. OECD Ülkelerinin Etkinlik Değerlerine Göre Sıralaması (PISA 2015)

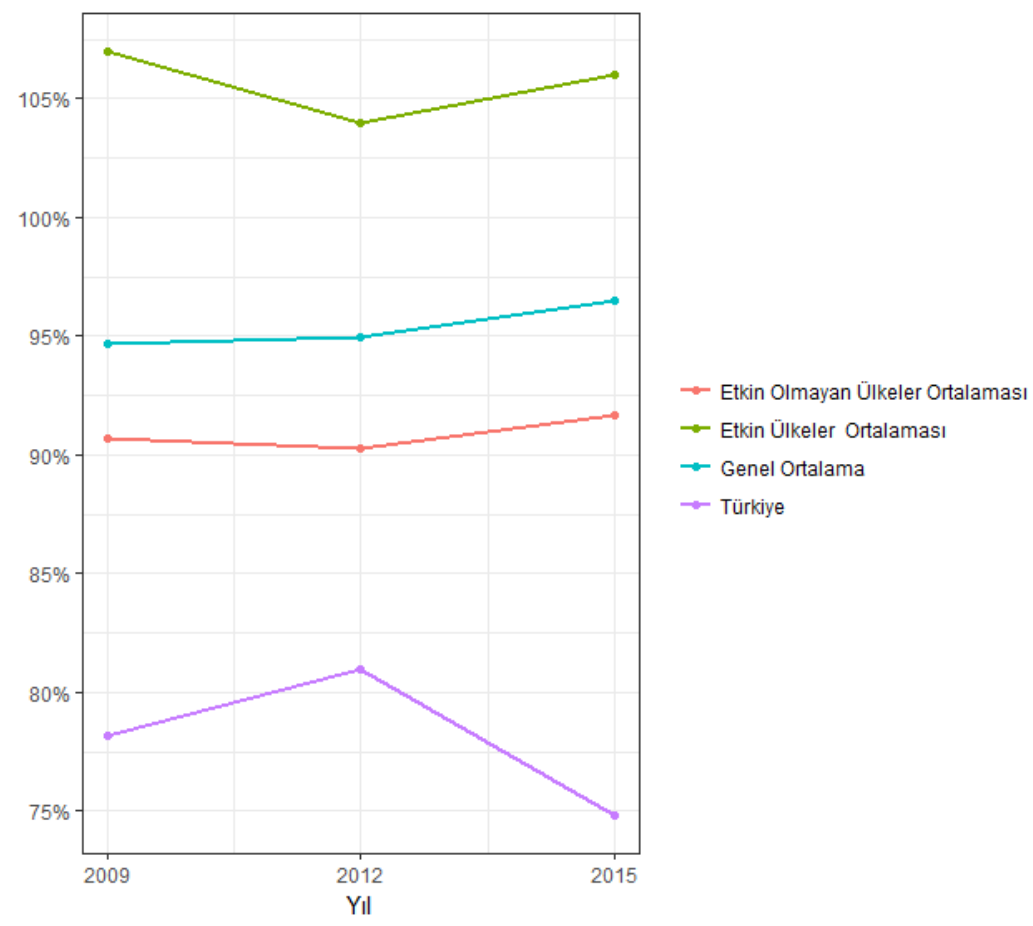

Şekil 4. Etkinlik Oranının Dönemsel Değişimi

Şekil 4 incelendiğinde üç dönemlik periyotta genel ortalamanın, etkin olan ve olmayan ülke ortalamalarının çok küçük değişiklikler gösterdiği söylenebilir. Buna karşın Türkiye etkinlik oranının genel ortalamaya göre daha fazla dalgalanma yaşadığı görülmektedir. Ayrıca Türkiye etkinlik oranın yine genel ortalama ve etkin olan ve olmayan 
ülkeler ortalamalarının zıddı biçimde değişimler sergilediği gözlenmektedir. 2015 döneminde tüm ortalama oranlarda bir miktar yükseliş gözlenirken Türkiye oranı bir önceki döneme göre oldukça ciddi bir düşüş sergilemiştir.

\section{Sonuç ve Tartışma}

alışma kapsamında, OECD ülkelerinin eğitim kaynaklarını etkin kullanım durumları ve Türkiye'nin bu ülkeler arasındaki konumu PISA 2009, 2012 ve 2015 veri setleri üzerinden VZA analizi ile (girdi yönlü CCR modeli) araştırılmıştır. Bu bağlamda, son üç PISA dönemi için OECD ülkelerine ait öğrenci/öğretmen oranı, okul mevcudu, tam zamanlı öğretmen sayısı ve internete bağlı bilgisayar oranı girdileri ve matematik başarısı çıktısına dayalı olarak etkinlik değerleri hesaplanmıştır. Üç dönem için de etkinlik değeri hesaplanmış, Türkiye'nin OECD ülkeleri arasındaki yeri incelenmiş ve girdi değişkenlerinde yapılması önerilen değişiklikler belirlenmiştir.

Elde edilen sonuçlar incelendiğinde, Türkiye'nin üç dönem için de etkin olmayan ülkeler arasında yer aldığg görülmüştür. 2009 uygulaması için kaynakları etkin kullanabilme noktasında 78.19\% etkinlik puanı ile sondan dördüncü olurken, 2012 uygulamasında 80.98\% etkinlik puanı ile sondan üçüncü olmuştur. 2015 uygulamasından elde edilen sonuçlara göre ise, etkinlik puanına göre Meksika'nın ardından en başarısız ikinci ülke olan Türkiye, 74.81\% etkinlik puanına sahip olmuştur. OECD ülkeleri etkinlik puanına göre sıralandığında, Türkiye'nin yıllar içerisinde birer basamak geriye gittiği görülmüştür. Türkiye'nin etkin ülke haline gelebilmesi için girdilerde yapması önerilen değişikliklere bakıldığında, üç dönem için de yalnıza öğretmen/öğrenci oranı girdisi için azaltma önerisi yapılmıştır. Okul mevcudu, tam zamanlı öğretmen sayısı ve internete bağlı bilgisayar oranı girdileri üzerinde bir değişiklik önerisi üç dönem için de olmamıştır. Analiz sonuçlarına göre, yalnızca öğretmen/öğrenci oranının önerilen şekilde azaltılmasının Türkiye'nin etkin ülke durumuna gelmesini sağlayacağı sonucuna varılmıştır.

Çalışmada elde edilen bulgular, Lorcu ve Acar-Bolat (2015)'in Türkiye'deki ve Avrupa Birliği üyesi ülkelerdeki ortaöğretim düzeyindeki eğitimin etkinlik değerlerini VZA yöntemiyle PISA 2009 verileri üzerinden karşılaştırdıkları çalışma sonuçlarıyla benzerlik göstermektedir. İlgili çalışmada, girdi değişkenleri olarak Öğrenci/Öğretmen oranı ve eğitim harcamalarının GSYİH içerisindeki payı, çıktı değişkenleri olarak ise Matematik, Fen ve Okuma okuryazarlığı puanları kullanılmıştır. Elde edilen sonuçlar, Türkiye'nin etkin ülkeler arasında yer almadığını ve Türkiye'nin Öğrenci/Öğretmen oranının azaltılması gerektiğini göstermiştir. Benzer şekilde, Demir ve Depren (2010) tarafından yapılan ve Türkiye'deki ortaokulların etkinliği PISA 2006 verileri bağlamında veri zarflama analizi kullanılarak değerlendirildiği çalışmalarında Öğrenci/Öğretmen oranının azaltılması gerektiği vurgulanmıştır. İlgili çalışmada, girdi değişkeni olarak okul mevcudu ve öğrenci/öğretmen oranı, çıktı değişkeni olarak ise Matematik, Fen ve Okuma okuryazarlığı puanları alınmış; çalışma sonucunda özellikle öğrenci/öğretmen oranı değişkeninin azaltılması gerektiği sonucuna ulaşılmıştır.

Yapılan çalışmadan elde edilen sonuçlar, kullanılan girdi ve çıktı değişkenleriyle sınırlıdır. Bundan sonraki araştırmalarda, farklı girdi ve çıktı değişkenleri ile çalışmanın tekrarlanması önerilebilir. Ayrıca, çalışma kapsamında karar verme birimi olarak OECD ülkeleri alınmış ve Türkiye'nin OECD ülkeleri arasındaki yeri incelenmiştir. Farklı ülkeler de dâhil edilerek çalışma tekrarlanabilir. 


\section{Extended Summary}

\section{Introduction}

The Programme for International Student Assessment (PISA) is a survey which aims to measure how well 15-year-old students are prepared to meet the challenges of todays' modern societies (OECD, 2017). The results of this survey can be used for making international comparisons, setting standards to develop the educational level of a country and identify strengths and weaknesses of educational systems (Taş, Arıcı, Ozarkan \& Özgürlük, 2016). By examining the characteristics of high-performing education systems, PISA results help administrators and educators to identify effective policies that can be adopted to their local context (Yuan, Ying \& Shan, 2016). Similarly, Aydın, Selvitopu, and Kaya (2018) stated that PISA results are important since they provide multidimensional and longitudinal data related to countries' educational level and general economic situation.

The first PISA survey took place in 2000 and has been repeated every three years. Turkey first participated in the PISA survey in 2003 and has continued to take part in the following periods. When mathematical literacy scores in the last three periods (PISA 2009, 2012 and 2015) were examined, Turkey's average score was lower than both OECD countries and all participating countries. Turkey, which is an OECD member, has an obviously lower average score than the OECD average and it is important to investigate the reasons for this situation.

In this research, the aim was to investigate the position of Turkey in relation to OECD countries in terms of effective use of resources in the last three cycles of PISA and the change of efficiency rate in those cycles. In the context of this purpose, the following research problems were asked;

1. According to the PISA 2009, 2012 and 2015 survey results,

- Which countries have used their educational resources effectively?

- Where is Turkey positioned in relation to other OECD countries in terms of effective usage of resources?

- What kind of changes could be made in order to increase Turkey's efficiency value?

\section{Method}

A survey design was used in this research in order to investigate OECD countries' efficient use of resources and Turkey's position among those countries.

The data of this study consisted of student performance results in mathematics tests and four school questionnaire variables in the last three PISA survey cycles (PISA 2009, 2012 and 2015). The number of OECD countries participating in PISA was 33 for the PISA 2009 and 2012 surveys and was 32 for the PISA 2015 survey, after countries with missing values were excluded from the analysis.

School questionnaires and achievement tests which were used in PISA 2009, 2012 and 2015 were used as data collection tools. School questionnaires were examined and variables which were common for all OECD countries in each of the three PISA cycles were identified as input variables. Mathematical literacy scores in those three cycles were used as the output variable.

EMS software was used for data analysis with the input oriented CCR model.

\section{Findings}

Findings related to efficiency values and changes which could be made on input variables were examined separately for the three cycles. Lastly, Turkey's position and situation in the last three PISA cycles were considered.

\section{PISA 2009}

According to data envelopment analysis results, only 8 OECD countries out of 33 used their resources efficiently, while the others were not able to. The most efficient country on resource use was Portugal and the least efficient one was Mexico. Turkey was among the non-efficient countries with a $78.19 \%$ efficiency value and placed in the $30^{\text {th }}$ position among 33 countries in terms of efficient use of resources. In order to increase Turkey's efficiency value, it is recommended decreasing the student/teacher ratio by 3.05 units.

\section{PISA 2012}

According to the results, 11 OECD countries out of 33 used their resources efficiently while the others were unable to. The most efficient country on resource use was Luxemburg and the least efficient one was Mexico. Turkey was 
among the non-efficient countries, similar to the PISA 2009 results. It was placed in $31^{\text {st }}$ position among 33 countries with an $81 \%$ efficiency value. In order to increase Turkey's efficiency value, it is recommended decreasing the student/teacher ratio by 3.14 units.

\section{PISA 2015}

The results indicated that 11 OECD countries had efficient resource use value, out of 32 countries. The most efficient country on resource use was Portugal and the least efficient one was Mexico. Turkey was among the non-efficient countries, similar to the PISA 2009 and 2012 results. It was placed in $31^{\text {st }}$ position among 32 countries, with a 75\% efficiency value. In order to increase Turkey's efficiency value, it is recommended decreasing the student/teacher ratio by 1.50 units.

When Turkey's situation in terms of efficient resource usage was investigated, it was among the non-efficient countries in each of the three PISA cycles. Turkey could not benefit from its resources efficiently in any cycle and the average efficiency rate was significantly below the OECD average. In addition, Turkey's efficiency score changed in an opposite manner to the overall average efficiency. In the PISA 2015 cycle, while the overall average, efficient country's average and non-efficient country's average scores increased, Turkey's efficiency value decreased significantly according to previous cycles. Another prominent finding is that Turkey should decrease the student/teacher ratio to be an efficient country member, according to all three cycles.

\section{Discussion and Conclusion}

The results of this study indicated that Turkey was placed among the non-efficient countries in terms of efficient resource use in each of the three cycles. Its position was among the last four in 2009 and the last three in 2012, with efficiency scores of 78.19\% and 80.98\% respectively. In the PISA 2015 survey, Turkey was the second least efficient country after Mexico with a $74.81 \%$ efficiency value. As can be seen, Turkey's position among OECD countries dropped down one step in the cycles from 2009 to 2015. The recommended change in input variables in order to increase Turkey's efficiency value was to decrease the student/teacher ratio for each of the three cycles. In a similar way, previous studies showed that the student/teacher ratio should be decreased in Turkey (Lorcu \& Acar-Bolat, 2015; Demir \& Depren, 2010).

These results were limited to the input and output variables used in this study. In further studies, this research may be repeated with different input and output variables and with decision making units other than OECD countries. 


\section{Kaynakça / References}

Agasisti, T. (2013) The efficiency of Italian secondary schools and the potential role of competition: A data envelopment analysis using OECD-PISA 2006 data. Education Economics, 21(5), 520-544. doi: 10.1080/09645292.2010.511840

Aladağ, Z., Alkan, A., Güler, E. \& Özdin, Y. (2018). Akademik birimlerin veri zarflama analizi ve promethee yöntemleri ile performans değerlendirmesi: Kocaeli üniversitesi örneği. Erciyes Üniversitesi Fen Bilimleri Enstitüsü Fen Bilimleri Dergisi, $34 \quad$ (1), 1-13. Retrieved from http://dergipark.gov.tr/erciyesfen/issue/37078/406003

Aydın, A., Selvitopu, A. \& Kaya, M. (2018). Eğitime yapılan yatırımlar ve PISA 2015 sonuçları: Karşılaştırmalı bir inceleme. İlkögretim Online, 17(3), 1283-1301. doi:10.17051/ilkonline.2018.466346

Bal, V. (2013). Vakıf üniversitelerinde veri zarflama analizi ile etkinlik belirlenmesi. Manas Sosyal Araştırmalar Dergisi, 2(1), 1-20.

Banker R. D., Charnes, A. \& Cooper, W. W. (1984). Some models for estimating technical and scale inefficiencies in data envelopment analysis. Management Science, 30(9), 1078-1092.

Bektaş, A. (2007). Ankara'daki özel liselerin etkinliğinin veri zarflama analizi ile ölçümü. (Yayımlanmamış Yüksek Lisans Tezi). Gazi Üniversitesi, Ankara. http://tez2.yok.gov.tr/ adresinden erişildi.

Berberoğlu, G. \& Kalender, İ. (2005). Öğrenci başarısının yıllara, okul türlerine, bölgelere göre incelenmesi: ÖSS ve PISA analizi. Eğitim Bilimleri ve Uygulama, 4(7), 21-35.

Charnes, A., Cooper W.W. \& Rhodes, E. (1978). Measuring the efficiency of decision making units. European Journal of Operational Research, 2(6), 429-444.

Cuban, L. (2001). Oversold and underused: Computers in the classroom. Harvard University Press, Cambridge.

Çakmak, E. \& Örkcü, H. (2016). Türkiye'deki illerin etkinliklerinin sosyo-ekonomik temel göstergelerle veri zarflama analizi kullanarak incelenmesi. Karabük Üniversitesi Sosyal Bilimler Enstitüsü Dergisi, 6 (1), 30-48.

Demir, A. \& Bakırc1, F. (2004). OECD üyesi ülkelerin ekonomik etkinliklerinin veri zarflama analiziyle ölçümü, Atatürk Üniversitesi İktisadi ve İdari Bilimler Dergisi, 28(2), 109-132.

Demir, İ. \& Depren, Ö. (2010). Assessing Turkey's secondary schools performance by different region in 2006. Procedia Social and Behavioral Sciences, 2, 2305-2309. doi: 10.1016/j.sbspro.2010.03.326

Demir, İ. , Depren, Ö. \& Kılıç, S. (2014). Türkiye'de farklı bölgelerdeki ortaöğretim okullarının etkinliğinin veri zarflama analizi ile ölçülmesi. The International Journal of Research in Teacher Education, 1 (1), 52-64.

Döş, İ. \& Atalmış, E . (2016). OECD verilerine göre pisa sınav sonuçlarının değerlendirilmesi. Abant İzzet Baysal Üniversitesi Eğitim Fakültesi Dergisi, 16 (2), 432-450. doi:10.17240/aibuefd.2016.16.2-5000194936

Egalite, A. J. \& Kisida, B. (2016) School size and student achievement: A longitudinal analysis. School Effectiveness and School Improvement, 27 (3), 406-417, doi: 10.1080/09243453.2016.1190385

Erpolat, S. (2011). Veri Zarflama Analizi. Evrim Yayınevi, İstanbul. 
Gavurova, B., Kocisova, K., Belas, L. \& Krajcik, V. (2017). Relative efficiency of government expenditure on secondary education. Journal of International Studies, 10(2), 329-343. doi:10.14254/2071-8330.2017/10-2/23

Karasar, N. (2014). Bilimsel araştırma yöntemi (26. Baskı.). Ankara: Nobel Yayınları.

Koc, N. \& Celik, B. (2015). The impact of number of students per teacher on student achievement. Procedia - Social and Behavioral Sciences, 177, 65-70. doi:10.1016/j.sbspro.2015.02.335)

Kyule A, Kangu M, Wambua, Mutinda B. \& Kamau S. (2014). Strategizing on cost: Effect of part time lecturers on university education in Kenya. Prime Journal of Social Science, 3(2), 603-607.

Leszinske, E., Jolley, M. \& Bryant, M. (2012). Contingent Faculty: Exploring Adjunct Assessment in Higher Education Environments. University of Nebraska-Lincoln, Lincoln, NE 68588-0360

Lorcu, F. \& Acar-Bolat, B. (2015). Comparison of secondary education PISA results in european member states and Turkey via DEA and SEM. Journal of WEI Business and Economics, 4(3), 7-17.

OECD (2012), "How Does Class Size Vary Around the World?", Education Indicators in Focus, No. 9, OECD Publishing, Paris, https://doi.org/10.1787/5k8x7gvpr9jc-en.

OECD (2016), PISA 2015 Results (Volume II): Policies and Practices for Successful Schools, PISA, OECD Publishing, Paris, https://doi.org/10.1787/9789264267510-en.

OECD. (2017). PISA 2015 technical report. OECD Publishing. http://www.oecd.org/pisa/sitedocument/PISA-2015technical-report-final.pdf adresinden erişildi.

Özkan-Aksu, E. \& Temel-Gencer, C. (2018). Veri zarflama analizi ile OECD ülkelerinin çevre performansının incelenmesi. Uluslararası İktisadi ve İdari İncelemeler Dergisi, 18, 191-206. doi: 10.18092/ulikidince.353933

Sarı, Z. (2015). Data envelopment analysis and an application. (Yayımlanmamış Yüksek Lisans Tezi). Hacettepe Üniversitesi, Ankara. http://tez2.yok.gov.tr/ adresinden erişildi.

Savaşç1, H. S. \& Tomul, E. (2013). The relationship between educational resources of school and academic achievement. International Education Studies, 6(4), 114-123. doi:10.5539/ies.v6n4p114

Suiçmez, H. (2014). Verimlilik ve etkinlik terimleri (Tarihsel bakış). Mülkiye Dergisi, 26 (234), 169-183.

Taş, U. E., Arıcı, Ö., Ozarkan, H. B. \& Özgürlük, B. (2016). Uluslararasi ögrenci değerlendirme programi PISA 2015 ulusal raporu. Ankara: Millî Eğitim http://odsgm.meb.gov.tr/test/analizler/docs/PISA/PISA2015_Ulusal_Rapor.pdf adresinden erişildi.

Thanassoulis, E., Portela, M. C. S. \& Despić, O. (2008). Data envelopment analysis: the mathematical programming approach to efficiency analysis. In H. O. Fried, C. A. K. Lovell, \& S. S. Schmidt (Eds.), The measurement of productive efficiency and productivity growth (pp. 251-420). New York, NY (US): Oxford University Press.

Thanassoulis, E., Portela, M.C. \& Allen, R. (2004) Incorporating Value Judgments in DEA. In: Cooper W.W., Seiford L.M., Zhu J. (eds) Handbook on Data Envelopment Analysis. International Series in Operations Research \& Management Science, vol 71. Springer, Boston, MA. 
Truong, D. (2014). Cloud-Based Solutions for Supply Chain Management: a post- adoption study. Proceedings of ASBBS, 21 (1).

Yalçın, S. \& Tavşancıl, E. (2014). Türk öğrencilerin pisa başarı düzeylerinin veri zarflama analizi ile yıllara göre karşılaştırılması. Kuram ve Uygulamada Eğitim Bilimleri, 14(3), 947-968. doi: 10.12738/estp.2014.3.1748

Yuan, Y., Ying, Q. \& Shan, M. (2016). Using DEA and CA Approaches for educational production efficiency: Evidence from Shanghai PISA Measurement. International Journal of Simulation Systems, Science \& Technology, 17(44).

Yorulmaz, Y., Çolak, İ., \& Ekinci, C. (2017). An evaluation of PISA 2015 achievements of OECD countries within income distribution and education expenditures. Turkish Journal of Education, 6 (4), 169-185. doi: 10.19128/turje.329755 